\title{
EFFECT OF REPEATED SOLUTION CYCLES ON CAST INCO 718
}

\author{
Borja Barasoain, Oscar Caballero \\ ${ }^{1}$ ITP (Industria de Turbopropulsores S.A.) \\ Parque Tecnológico Ed. 300, Zamudio, 48170, Spain
}

Keywords: INCO718, Solution heat treatment, Delta phase

\begin{abstract}
Solution heat treatment for INCO 718 cast alloy is typically performed at temperatures specified by aero engine manufacturers around $965^{\circ} \mathrm{C}$ which is the temperature where most Delta phase precipitation takes place. The generation of this amount of Delta phase is not subsequently followed by a higher temperature heat treatment that allows the re-dissolution of the Delta in the matrix. This paper describes the effect of multiple solution heat treatments on cast INCO 718 alloy emphasizing the metallurgical quality and mechanical properties of the cast alloy.
\end{abstract}

\section{Introduction}

The manufacturing methods applied for producing turbine components are fairly controlled and modifications to these methods are restricted by the aero engine manufacturers, as they could cause changes related to the mechanical properties of the components, which are thoroughly tested before accepting them for flying purposes.

Although INCO 718 is a well-known alloy, the effect of some processes connected to the manufacturing method are not yet completely understood or considered to a complete extent. An example of this is the application of multiple solution heat treatments to the alloy.

The current trend for manufacturing large INCO 718 alloy components is to design and make them as fabrications for reasons already explained elsewhere [1].

Cast parts are included in these fabrications and they usually require some weld repair operations to heal the typical casting defects, such as shrinkages, porosities and inclusions. After removing these defects by grinding, the resulting voids need to be rebuilt on the parts by adding material by welding.

In order to remove the residual stresses produced during the weld repair process and to leave the material in the best condition for subsequent operations, a solution heat treatment is normally required after welding.

Subsequent inspections might detect additional defects, forcing new repair cycles and thus, additional solution heat treatments to be carried out. The effect of these heat treatments on the microstructure of cast INCO 718 alloy has been studied during this investigation [2] [3].

Solution heat treatment for cast INCO 718 alloy is typically performed at temperatures specified by the aero engine manufacturers around $965^{\circ} \mathrm{C}$, which causes indeed the solution of gamma prime and gamma double prime precipitates, however, it is also the temperature where most 
Delta phase precipitation takes place (Figure 1). Delta phase is an orthorhombic $\mathrm{Ni}_{3} \mathrm{Nb}$ phase known to form during elevated temperature exposure.

The Delta phase is expected to precipitate and grow upon slow cooling from high temperature, while at intermediate and high cooling rates, the metastable $\gamma$ '" should be favored [4].

The generation of this Delta phase is not subsequently followed by a higher temperature heat treatment that allows the re-dissolution of the Delta in the matrix, so it is in fact remaining there, taking some of the Niobium needed to form the gamma double prime hardening phase [5]. Consequently, microstructural and mechanical changes would be expected by the accumulation of solution heat treatments.

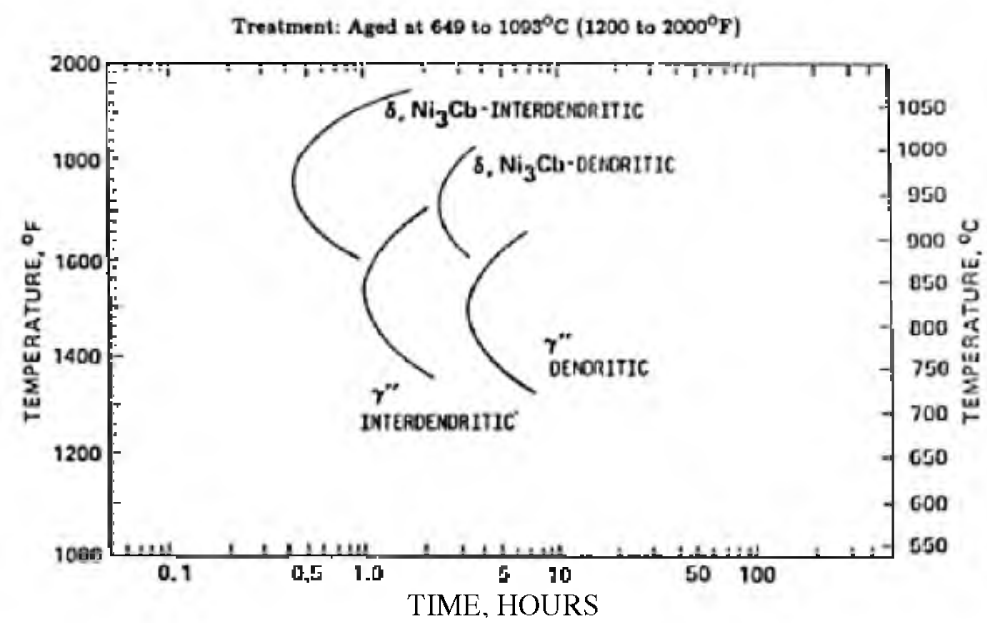

Figure 1. Time-temperature-transformation diagram for IN-718 [6].

\section{Experimental Procedure}

$\underline{\text { Material }}$

Cast INCO 718 alloy according to AMS5383 specification has been used in this study. The typical chemical composition of the alloy is quoted on Table 1.

Table 1. INCO 718 Chemical composition.

\begin{tabular}{|l|c|c|}
\hline Element & Min & Max \\
\hline $\mathrm{C}$ & - & 0.08 \\
\hline $\mathrm{Mn}$ & - & 0.35 \\
\hline $\mathrm{Si}$ & - & 0.35 \\
\hline $\mathrm{P}$ & - & 0.015 \\
\hline $\mathrm{S}$ & - & 0.015 \\
\hline $\mathrm{Cr}$ & 17.00 & 21.00 \\
\hline $\mathrm{Ni}$ & 50.00 & 55.00 \\
\hline $\mathrm{Mo}$ & 2.80 & 3.30 \\
\hline $\mathrm{Nb}$ & 4.75 & 5.50 \\
\hline $\mathrm{Ti}$ & 0.65 & 1.15 \\
\hline $\mathrm{Al}$ & 0.40 & 0.80 \\
\hline $\mathrm{Ti}+\mathrm{Al}$ & - & 1.75 \\
\hline
\end{tabular}




\begin{tabular}{|l|c|c|}
\hline Element & Min & Max \\
\hline Co & - & 1.00 \\
\hline $\mathrm{B}$ & - & 0.006 \\
\hline $\mathrm{Fe}$ & \multicolumn{2}{|c|}{ Remainder } \\
\hline
\end{tabular}

\section{$\underline{\text { Test Samples }}$}

Two different kinds of samples were used to investigate how repeatedly solution heat treatments affects cast INCO 718 alloy in terms of microstructural and mechanical behavior. These were Separately Cast Test Bars (from now on SCTBs) and Integrally Cast Test Bars (from now on ICTBs).

There are differences between these two kinds of test samples during the casting process; preheating temperature of ICTBs is higher than the pre-heating temperature of the SCTBs, the pouring temperature of ICTBs is also higher than the SCTBs pouring temperature. These differences on the pre-heating and pouring temperatures have a clear effect on the microstructure of the alloy as will be explained later on. Furthermore, those differences increase the scatter of the mechanical results obtained from ICTBs.

Additionally, 24 sections from a cast plate with three different thicknesses were also analyzed (called as High Thickness Test Bars, from now on HTTB).

The plate was $110 \mathrm{~mm}$ in length, each section was 15,20 and $25 \mathrm{~mm}$ thick and each slice was 35 $\mathrm{mm}$ in length. An overview of the cast plate is shown in Figure 2.

These sections were cut into 4 groups with 6 pieces in each group to be able to perform $1,3,5$ and 7 solutions cycles. The solution heat treatments followed by these cast plate is shown in Table 2.

Metallographic analysis using optical and scanning electron microscopy of the mounted test samples were performed. The etchant used was $2,6 \mathrm{~g} \mathrm{CuCl} 2 ; 2,6 \mathrm{~g} \mathrm{FeCl}_{3} ; 52,6 \mathrm{~cm}^{3} \mathrm{HCl} ; 10,5 \mathrm{~cm}^{3}$ $\mathrm{HNO}_{3} ; 36,9 \mathrm{~cm}^{3}$ distilled water. The amount of Delta phase was specifically measured for allow a future relation with mechanical properties.

The samples were tensile tested at Room Temperature (from now on RT) and at $600{ }^{\circ} \mathrm{C}$.

All the material was X-Ray inspected. 


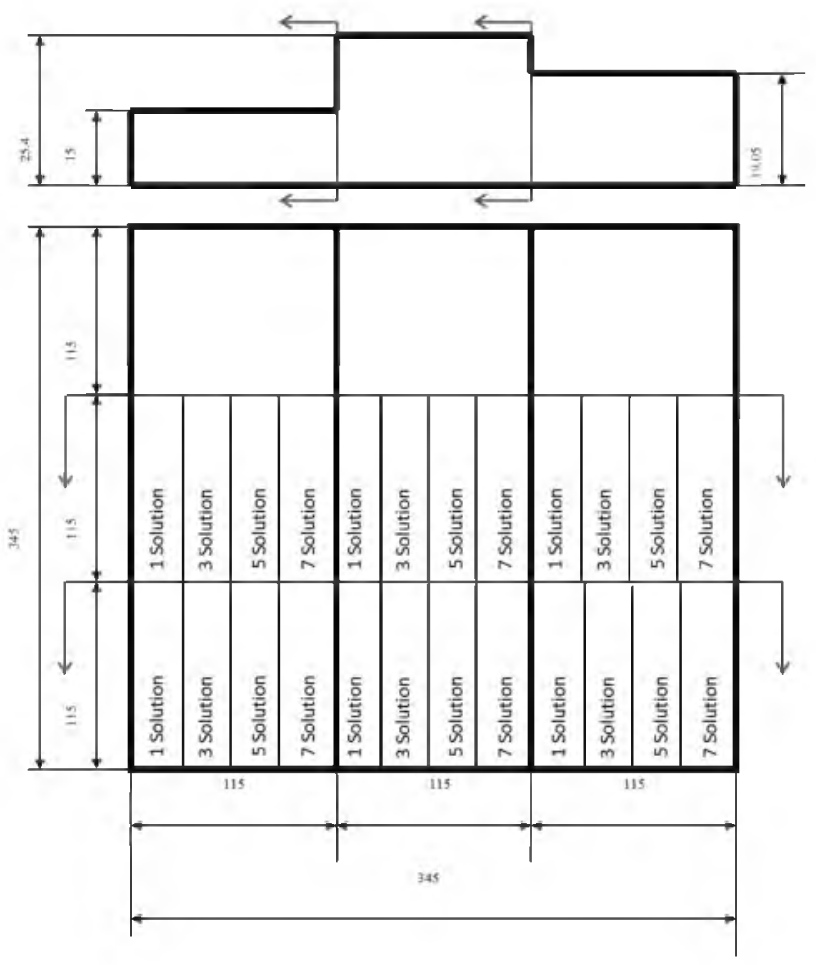

Figure 2. Sample cut up from the casting plate.

\section{$\underline{\text { Heat Treatment }}$}

Neither the SCTBs nor the HTTBs were subjected to a Hot Isostatic Pressure (from now on HIP) cycle as it was supposed that HIP would only improve the mechanical properties of the test samples obtained from the cast plate.

The heat treatment applied to the SCTB and HTTB test samples were homogenization, solution and aging, while the heat treatment cycle applied to the ICTBs test samples were homogenization, HIP, solution and aging.

The solution plus precipitation heat treatment is shown in Table 2 and it was applied to the different samples up to seven times.

Table 2. Solution + Precipitation Heat Treatment.

\begin{tabular}{|l|}
\hline Solution Heat Treatment \\
$965^{\circ} \mathrm{C} / 1 \mathrm{~h} /$ Vacuum/GFQ \\
\hline Precipitation Heat Treatment \\
$720^{\circ} \mathrm{C} / 8 \mathrm{~h} /$ Vacuum \\
Furnace Cool: $45-65^{\circ} \mathrm{C} / \mathrm{h}$ to $620^{\circ} \mathrm{C}$ \\
$620^{\circ} \mathrm{C} / 8 \mathrm{~h} / \mathrm{GFQ}$ \\
\hline
\end{tabular}

$\underline{\text { Measurement Methodology }}$

The methodology applied to measure the amount of Delta phase in each of the analyzed samples consists of selecting the five 1,25 $\times 1,00 \mathrm{~mm}$ fields with the higher Delta phase quantity of the whole analyzed surface and binarize the images using the Leica QWin software to obtain the percentage of area occupied by Delta phase. 
The measurements were made at a magnification of $\times 200$ in order to distinguish the Delta phase from other phases.

Is well known that the Delta phase appears as high-aspect needles, in or adjacent to the interdendritic areas, in general up to 40 microns in length, except along some grain boundaries where small needles are present [7].

\section{Results and discussion}

\section{$\underline{\text { Microstructures }}$}

The Delta phase shown in the attached micrographs are located at or near the interdendritic areas due to the segregation which occurs during the casting process [8]. Laves phases were also found around those areas, and these were surrounded by Delta phase. This is reasonable as the dendrites are enriched in $\mathrm{Nb}$, which facilitates the precipitation of the Delta phase.

When comparing the microstructure of the three different samples, considerable differences can be observed.

The SCTB (Figure 3) and the HTTB (Figure 4) samples show a high presence of Delta phase while the ICTB (Figure 5) samples reveals a lower amount of Delta phase. The initial differences on the material condition have influenced the Delta phase amount.

Comparing the collected Delta phase measurements, it can be concluded that the initial state of the material has great influence with respect to the amount of Delta phase. It was also concluded that Delta phase measurements obtained from the studied samples are not statistically equivalent (means and variances), to a $95 \%$ confidence level.

The observed differences are caused by the different cooling rates of the samples; ICTBs cooling rate is slower than the SCTBs cooling rate, were the slowest samples belong to the HTTB. This is reasonable as the cast plates are the thickest ones being evaluated; additionally it contains geometrical changes within its section creating areas which solidify quicker than others.

Although the SCTB cooling rate is quicker than the ICTB cooling rate, this value has not been measured. The assumption is made due to the shape of the SCTB mold, and other variables as described below, which are related to the production method of each sample. This gives differences in results on the Delta phase content.

The ICTBs are cast with the parts, in the same cluster. The samples are stacked to the feeding channels, which are insulated with kaowool blankets to achieve a cooling rate slower than the part.

The SCTBs, as shown in Figure 6 are cast with the shape of the tensile test sample and no insulation is used with the aim of achieving good mechanical properties.

These differences regarding the cooling rates of the studied samples should imply differences in the Delta phase quantity, because quicker cooling rates imply lower times within the Delta phase field (see Figure 7). 


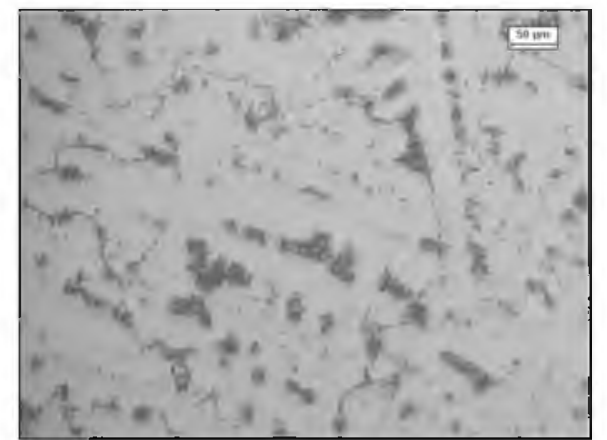

Figure 3. Delta phase presence in the SCTB samples for $1 \times$ solution heat treatment.

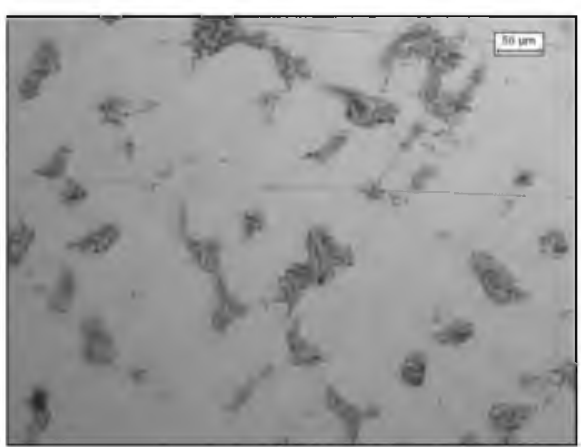

Figure 4. Delta phase presence in the IITTB samples for $1 \times$ solution heat treatment.

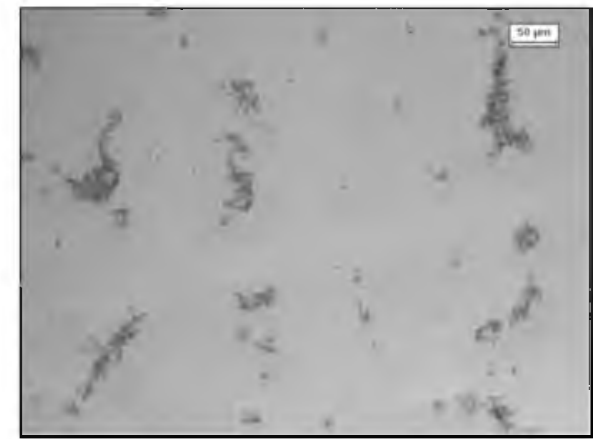

Figure 5. Delta phase presence in the ICTB samples for $1 \times$ solution heat treatment.

The HIP cycle, which ICTB were exposed, may have aid to the homogenization cycle, reducing the amount of segregations within the casting and finally meaning a lower quantity of Delta phase.

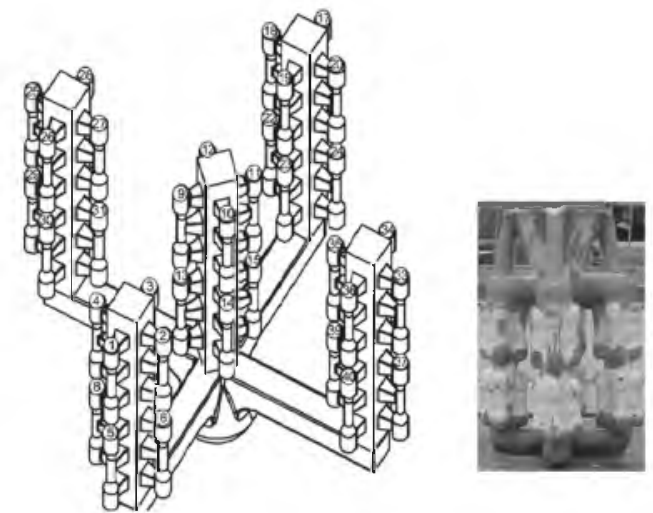

Figure 6. SCTB mold distribution. 


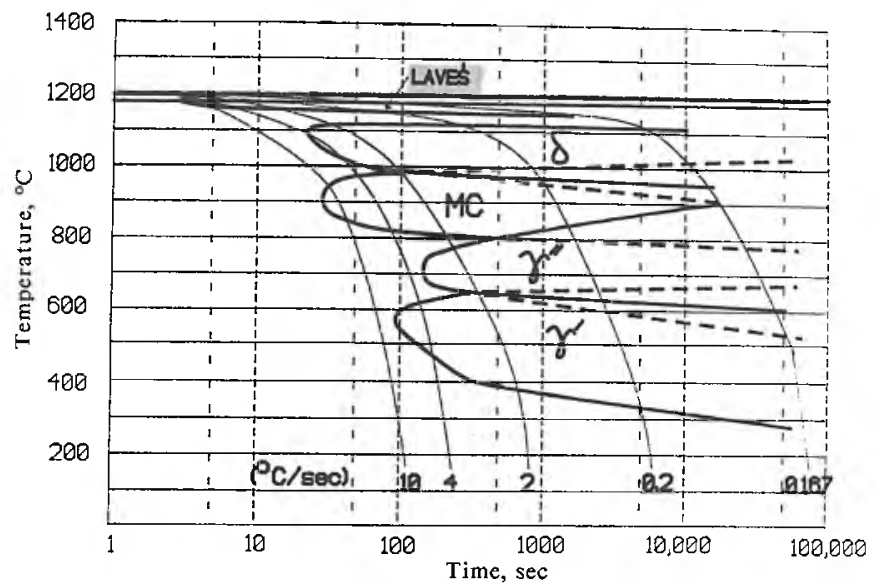

Figure 7. CCT diagram for alloy INCO 718. Image taken from [ref.4].

Notwithstanding the consistent Delta phase measuring method, microstructural differences were noted. These differences are due to the influence of the processing technique and specimen geometry. The statistical analysis made shows that the recorded data is not comparable (in terms of means and variances) between the three kind of samples. So, in order to know the Delta phase growth rate, the measurements for 3,5, and 7 solution heat treatments have been normalized per the mean value for one solution heat treatment per sample type. Using that operation, the typical Delta phase growth rate (how the quantity of Delta phase grows with the amount of solution heat treatments) is obtained (Figure 8).

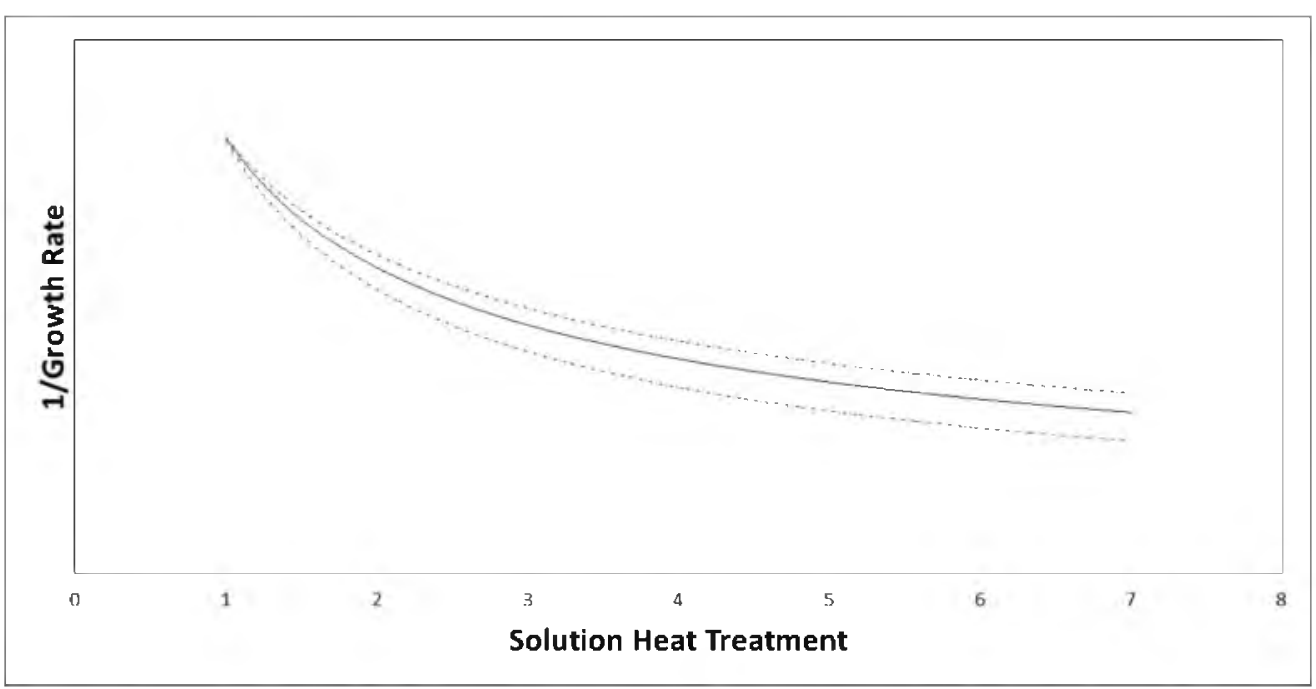

Figure 8. Inverse of Delta phase typical growth rate VS number of solution heat treatments (continuous line). Dashed lines represent Mean \pm Standard Deviation.

In order to evaluate the large effect of the cooling rate on the Delta phase precipitation, the samples obtained from the casting plate was further analyzed.

Considering the mold distribution shown in Figure 2, the Delta phase mean values were plotted considering section and number of solution heat treatments. Plotting and analyzing those values (see Figure 9) it can be concluded that the maximum Delta phase is found in the thicker sections of the cast plate.

Section 5 presents the highest levels of Delta phase when seven solution heat treatments are given, which is reasonable as it is in the middle of the thickest section of the plate ( $25 \mathrm{~mm}$ thick). 


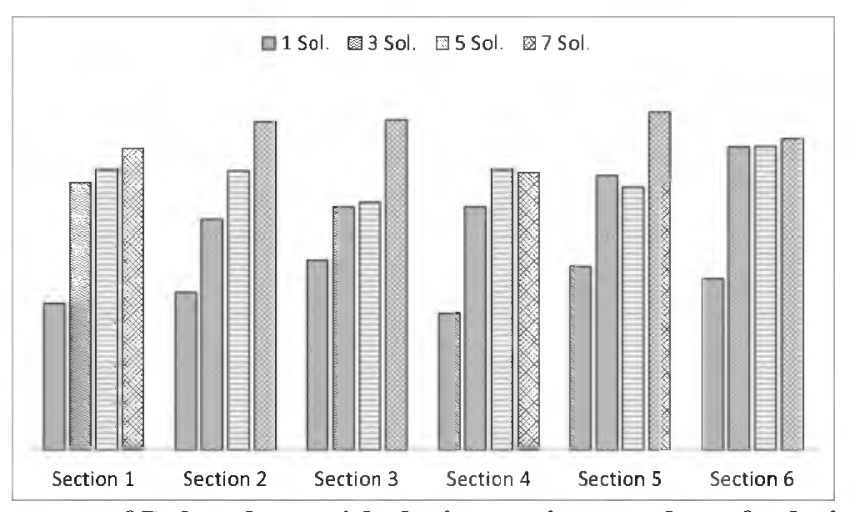

Figure 9. Typical amount of Delta phase with the increasing number of solution heat treatments.

Another variable that may have influenced on the Delta phase content is the HIP treatment. The ICTBs are subjected to the same heat treatments as the parts, which includes a HIP while the SCTBs and the HTTBs did not.

HIP was not deemed necessary for the SCTBs, because these kinds of samples are cast separately and the mold where the SCTBs are cast is designed to prevent any shrinkage problems.

Even though it was not the main objective of the present study, as far as it can be analyzed, HIP treatment has an influence on the percentage of precipitated Delta phase. Introducing a HIP cycle prior the solution heat treatments may generate a cleaner microstructure of cast INCO 718 alloy.

\section{Mechanical Properties}

A total amount of 182 tensile test results have been analyzed; 121 SCTBs, 61 at RT and 60 at $600{ }^{\circ} \mathrm{C}$ and 61 ICTBs, 31 at RT and 30 at $600^{\circ} \mathrm{C}$.

Results from this analysis shown differences between the SCTBs and the ICTBs for the different studied tensile parameters; Proof Stress at $0.2 \%$ elongation $(0.2 \% \mathrm{PS})$, Ultimate Tensile Strength (UTS), percentage of Elongation measured at five times the diameter (\%El 5D) and percentage of Area Reduction (\%RA).

All the mentioned parameters have been statistically analyzed and normalized against the correspondent base material, which is the group of samples with just one solution heat treatment at $\mathrm{RT}$ or $600^{\circ} \mathrm{C}$ respectively.

Focusing in the UTS, the relationship between the stress reduction and the number of solution heat treatments is shown in Figure 10. Analyzing the obtained curve, it is observed that the UTS reduction is around the $2 \%$ when the tensile test samples are subjected to seven consecutive solution heat treatments, with a typical content on Delta around $14 \%$. 


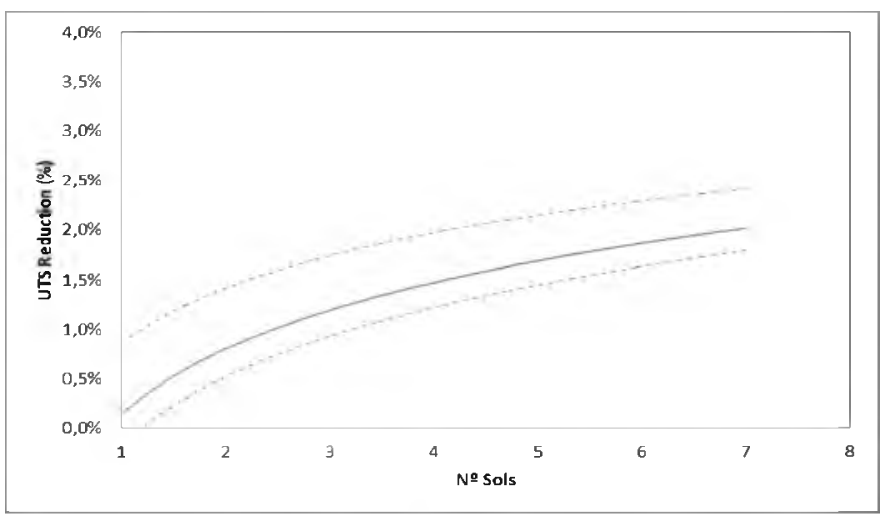

Figure 10. UTS reduction with the increasing number of solution heat treatments (continuous line). Dashed lines represent Mean \pm Standard Deviation

Applying the same analysis as for the UTS, but now for the $0.2 \%$ PS (Figure 11), it can be concluded that the reductions obtained for the $0.2 \% \mathrm{PS}$ property with the increasing number of solution heat treatments is slightly higher, for seven consecutive solution heat treatments the reduction is around $6 \%$.

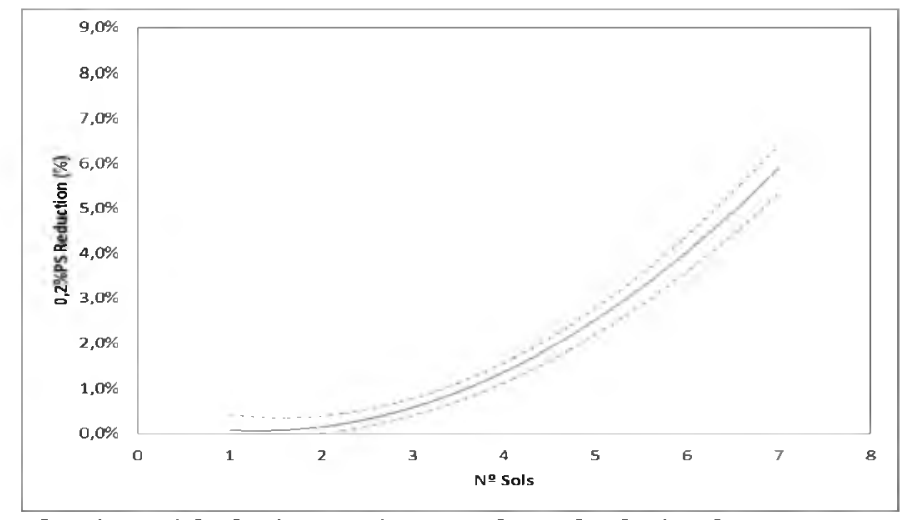

Figure 11. 0.2\% PS reduction with the increasing number of solution heat treatments (continuous line). Dashed lines represent Mean \pm Standard Deviation

Analysis of the ductility parameters, \%El 5D and \% AR, has been more complicated as the results reveals a large scatter. Furthermore the trend of the curves is not clear, the SCTBs subjected to seven solution heat treatments present \%El 5D typical values beyond the typical baseline results (one solution heat treatment).

Surprisingly for both, SCTBs and ICTBs, the \%El 5D typical results for 3 and 5 consecutive heat treatments are below the typical results of the baseline material (one solution heat treatment), which may imply an embrittlement of the cast alloy (see Figure 12 to Figure 15).

When analyzing the \%RA, the same observation as for the \%El 5D can be made. There is a great scatter in the results and there is not a strong trend disclosed (see Figure 16 to Figure 19). However, similar to what happened when the \%E1 5D is considered, when 2 additional solution heat treatments are applied to the test samples, a \%RA reduction is observed, this reduction is recovered when two additional solution heat treatments are given to the material (five solution heat treatments).

Few conclusions can be obtained regarding the ductility of the alloy with the increasing number of solution heat treatments. That is why a fracture surface analysis was carried out. 


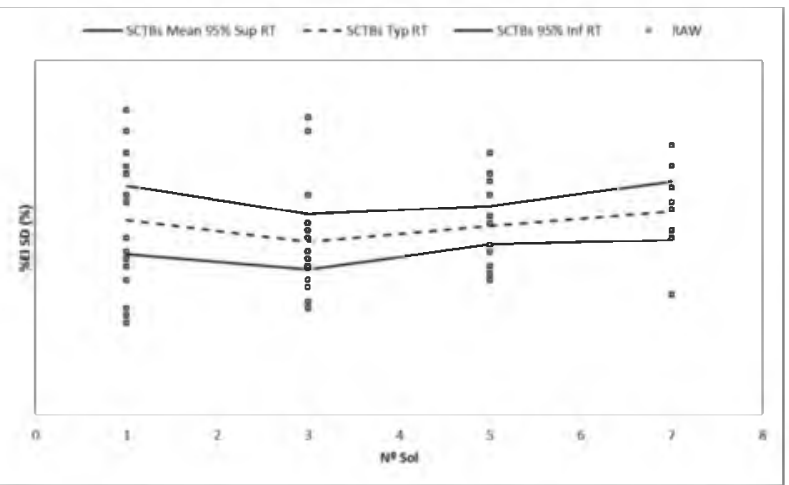

Figure 12. \% El 5D (\%) for the SCTBs at RT

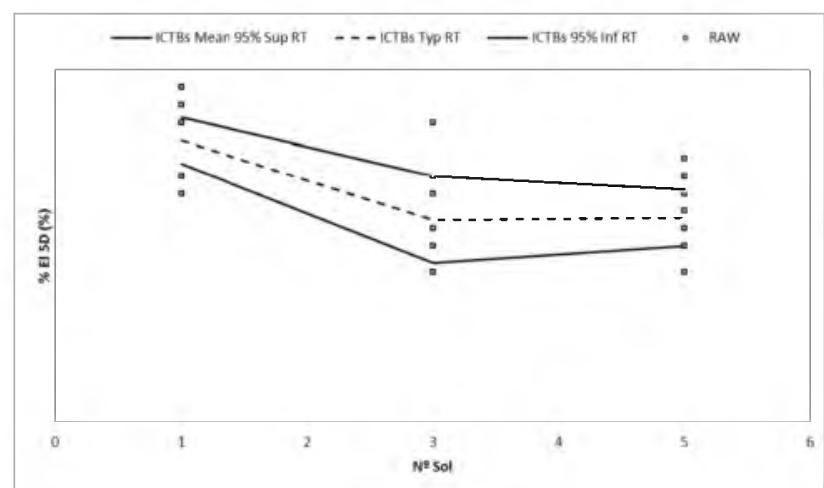

Figure 14. \% El 5D (\%) for the ICTBs at $22^{\circ} \mathrm{C}$

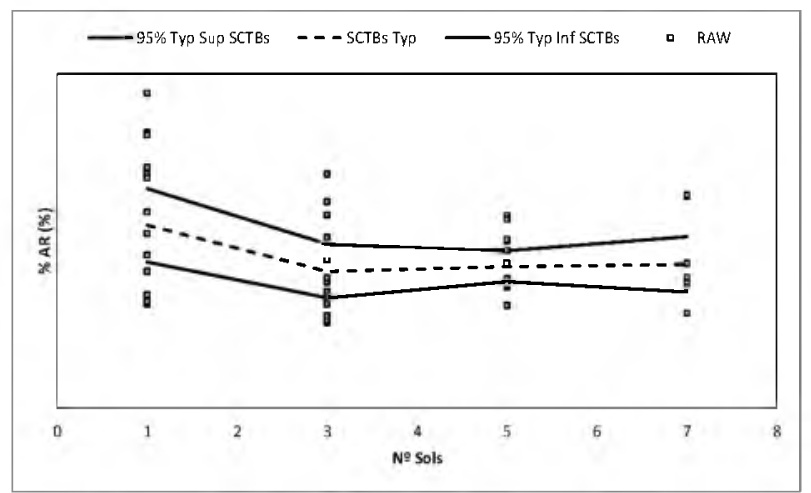

Figure 16. \% RA (\%) for the SCTBs at $22^{\circ} \mathrm{C}$

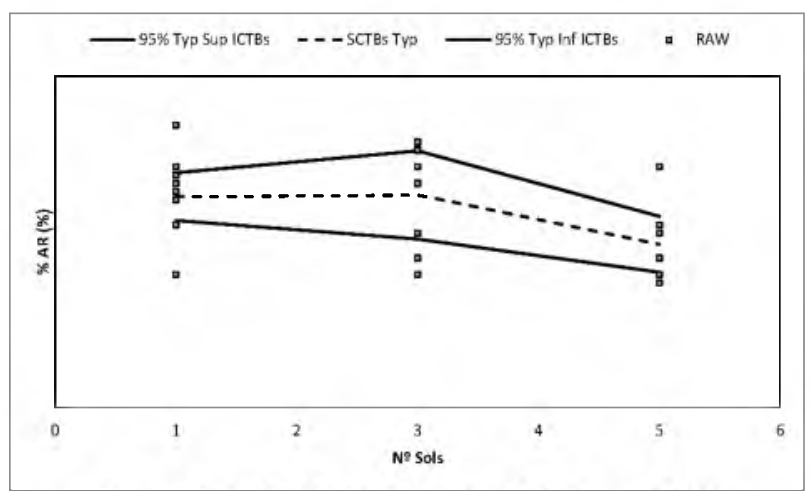

Figure $18 . \%$ RA $(\%)$ for the ICTBs at $22^{\circ} \mathrm{C}$

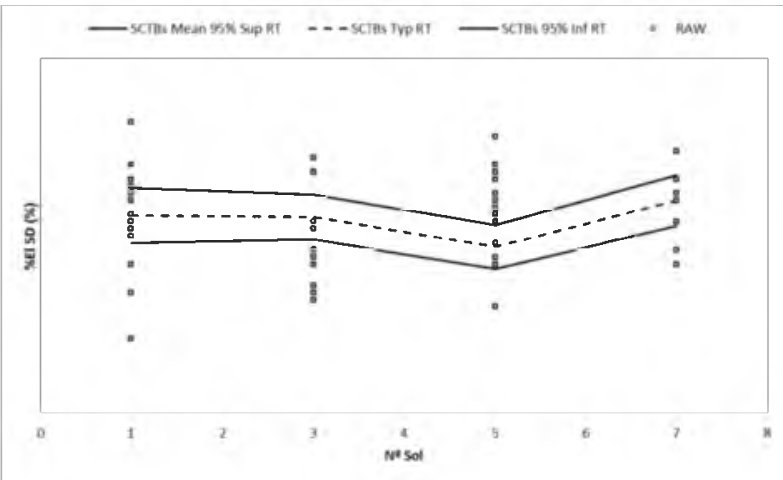

Figure 13. \%EI 5D (\%) for the SCTBs at RT

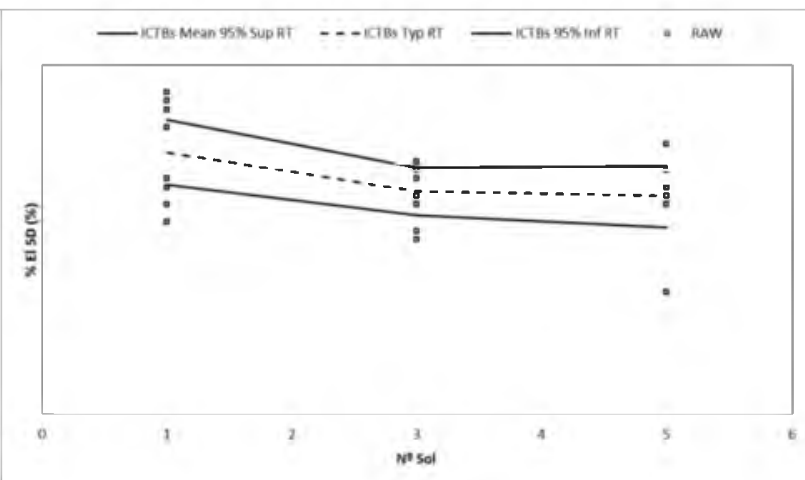

Figure 15. \%EI 5D (\%) for the ICTBs at $600^{\circ} \mathrm{C}$

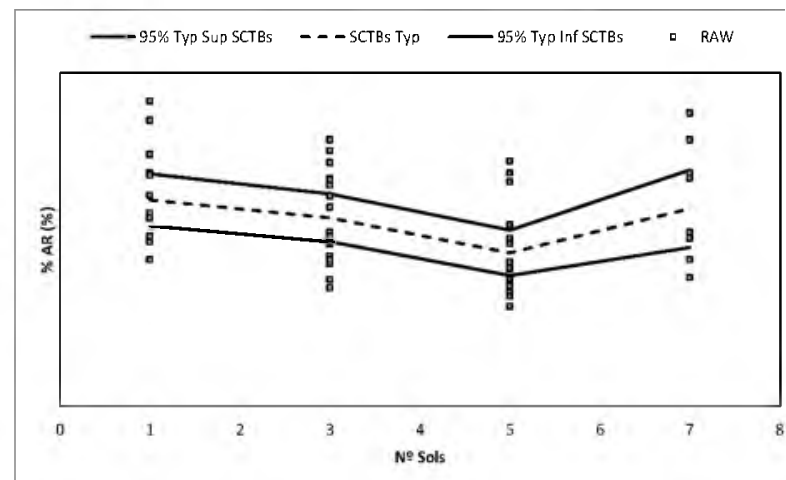

Figure 17. \% RA (\%) for the SCTBs at $600^{\circ} \mathrm{C}$

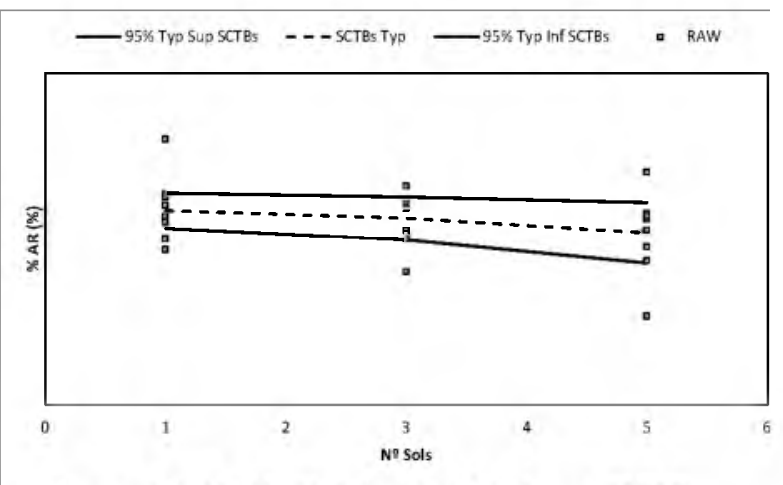

Figure 19. $\%$ RA $(\%)$ for the ICTBs at $600^{\circ} \mathrm{C}$ 


\section{Fracture Surface}

A metallographic analysis of the fracture surfaces were performed on four different samples tensile tested. Two selected samples from ICTBs and SCTBs respectively, one with the lowest amount of Delta phase and the other one with the highest content. The samples were analyzed using first optical microscopy and later SEM.

The four samples revealed an intergranular fracture, as commonly observed on tensile tests of this kind.

Figure 20 shows the fracture surfaces of two ICTBs, the left one with less than $1 \%$ (1 solution heat treatment) of Delta phase and the right hand side, one with $12.7 \%$ of Delta phase (5 solution heat treatments).
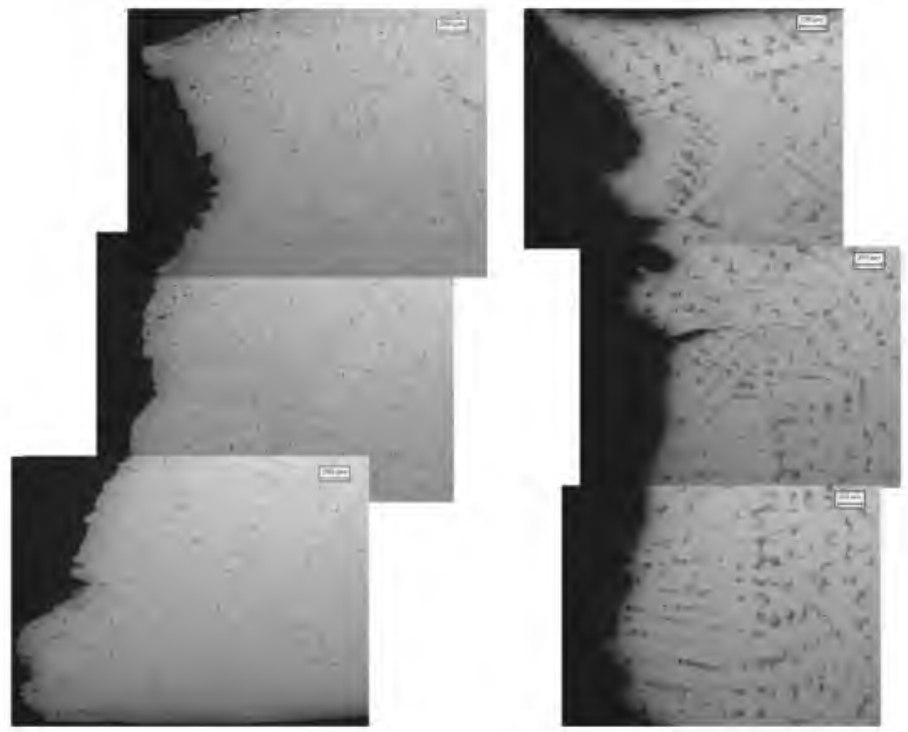

Figure 20. Fracture surface of the ICTBs

By analyzing Figure 21 and Figure 22, using SEM, no conclusion was possible to make as the fracture surfaces were very similar.
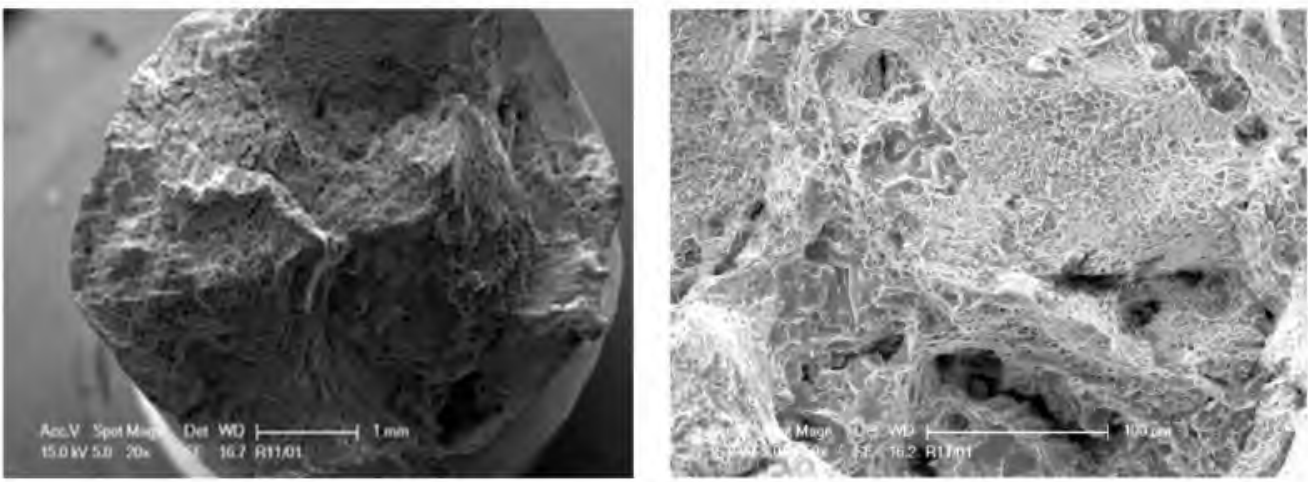

Figure 21. Fracture surface of the ICTB with the lowest content of Delta phase. 

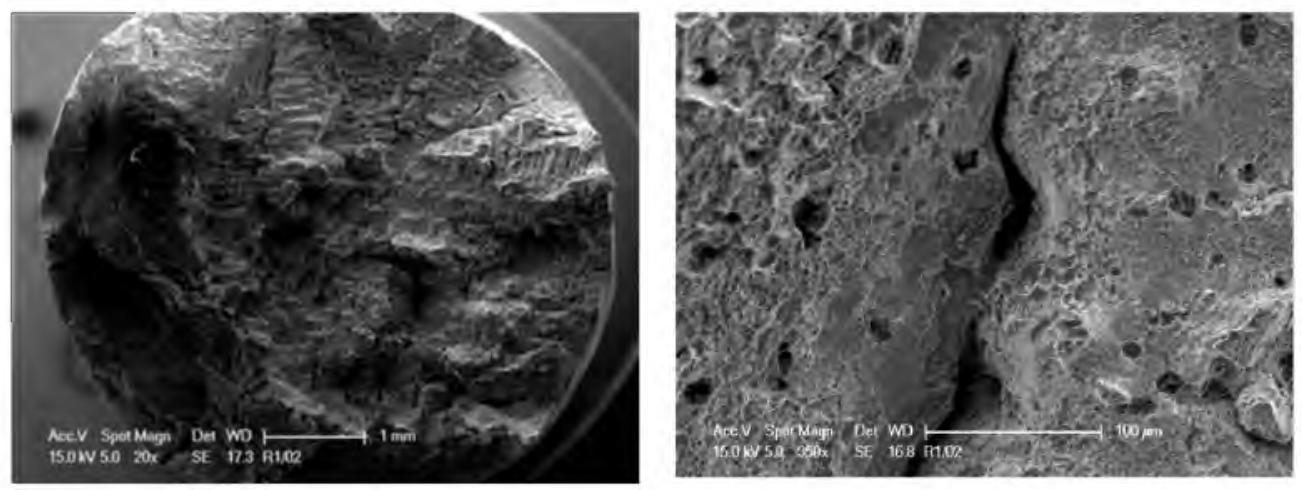

Figure 22. Fracture surface of the ICTB with the highest content of Delta phase.

The SCTBs were analyzed and as the quantity of Delta phase increases from $1.9 \%$ (1 solution heat treatment) to $22.7 \%$ (7 solution heat treatment), differences can be observed. The sample with the higher amount of Delta reveals less plasticity along the fracture surface (Figure 23 ).

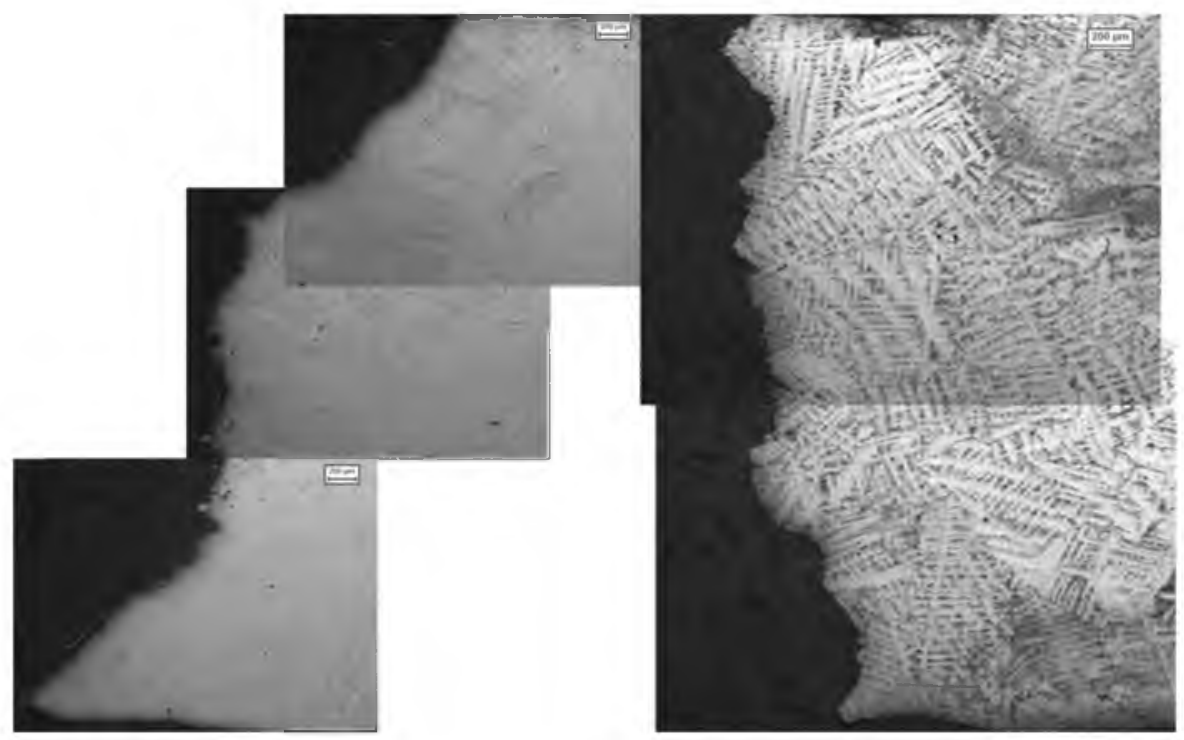

Figure 23. Fracture surface of the SCTBs

Differences between the samples are observed in the SEM. The sample with the highest amount of Delta phase there are more brittle areas (Figure 25) than the ones observed in the SCTB with low Delta phase content (Figure 24).
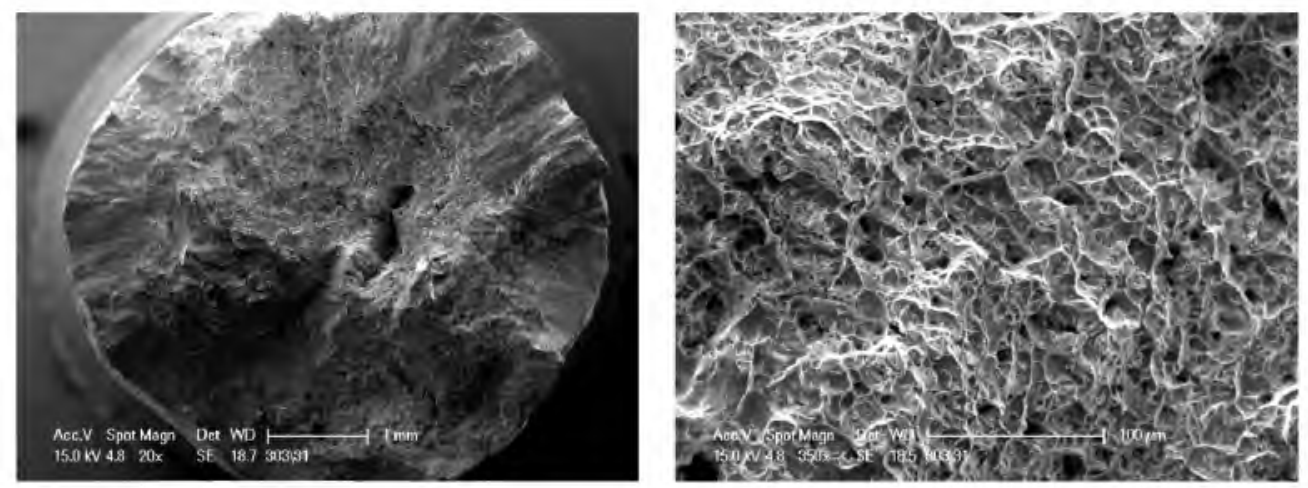

Figure 24. Fracture surface of the SCTB with the lowest content of Delta phase. 

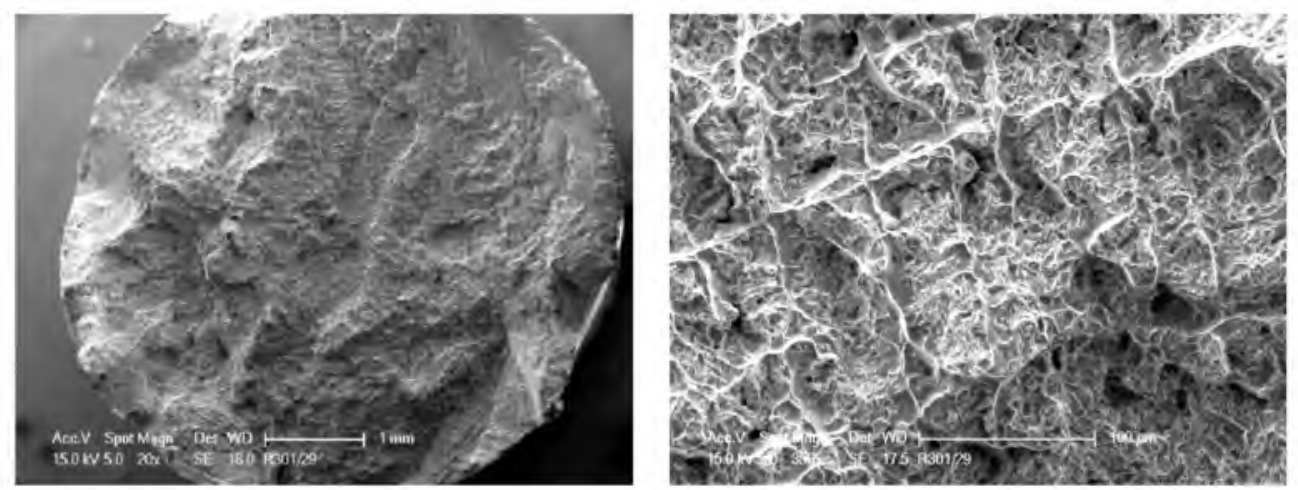

Figure 25. Fracture surface of the SCTB with the highest content on Delta phase.

When the elongation and the area reduction of the samples, with high Delta phase content is compared against the ones with low Delta phase content, a minimum drop on the ductility data has been observed, this may imply a minor embrittlement of the alloy.

A minimum reduction of the $0.2 \%$ Proof Stress has been also observed, which agrees with the previous observation.

\begin{tabular}{|c|c|c|c|}
\hline Sample & \%EI 5D (\%) & \%AR $(\boldsymbol{\%})$ & \% Delta \\
\hline ICTB & 17.0 & 29.0 & $<1.0$ \\
\hline ICTB & 12.0 & 18.0 & 12.7 \\
\hline SCTB & 18.5 & 31.5 & 1.9 \\
\hline SCTB & 16.0 & 19.5 & 22.7 \\
\hline
\end{tabular}

Table 3. \% EI 5D and \% AR for two ICTBs and two SCTBs

\section{Conclusions}

- Multiple solution heat treatments on cast INCO 718 alloy have a great influence on the amount of Delta phase. The growth rate of Delta phase increases with the increasing number of solution heat treatments.

- It seems to exist an asymptotic behaviour of the increase of Delta phase with the number of solution heat treatments. This may imply a saturation of Delta phase amount with the increase of solution heat treatments.

- The amount of Delta phase is clearly influenced by the cooling rate at which the test samples were subjected to. Slow cooling rates imply more segregation within the casting, so insulation of the mould and distance to the feed cup are parameters which have an influence on the cooling rate, thus these parameters will affect the initial amount of Delta phase.

- There is slight reduction in the UTS and 0.2\%PS with the increasing of number of solution heat treatments. This reduction does not seem to be too detrimental, at least not for the maximum number of seven solutions.

- The increase in the content of Delta phase caused a slight embrittlement of the analysed samples. This fact is proved with a minimum decrease of the elongation and the area reduction with the increasing number of solution heat treatments. 


\section{References}

[1] Seinturier, E. \& Paniagua, G. May. 2008. Structural Design of Aircraft Engines: Key Objects and Techniques.13-16.

[2] Bayless, E.O., Lovoy, C.V., McIlwaiin, M.C., Munafo, P. 1981. Considerations on Repeated Repairing of Weldments in Inconel 718 Alloy. George C. Marshall Space Flight Center, Alabama 35812. National Aeronautics and Space Administration Washington, D.C. 20546

[3] Russell, C.K., Nunes, A.C., Moore, D. 1991. The effects of Multiple Repairs on Inconel 718 Mechanical Properties. George C. Marshall Space Flight Center, Alabama 35852. National Aeronautics and Space Administration Washington, D.C. 20546.

[4] Niang, A., Viguier, B., Lacaze, J. 2010. Some Features of Anisothermal Solid-State Transformations in Alloy 718. Materials Characterization, vol 61 ( $\mathrm{n}^{\mathrm{o}}$ 5). pp. 525-534. ISSN $1044-5803$

[5] Cozar, R. \& Pineau, A. January 1973. Morphology of Gamma Prime and Gamma Double Prime Precipitates and Thermal Stability of Inconel 718 Type Alloys.

[6] Vander Voort, G.F. Atlas of Time-Temperature Diagrams for Nonferrous Alloys. Edited by. ISBN: 0-87170-428-5. Page 210.

[7] Hooijmans, J.W. \& Lippopld, J.C. 1997. Effect of Multiple Postweld Heat Treatments on the Weldability of Alloy 718., The Ohio State University and W. Lin, Pratt and Whitney, edited by E. A. Loria, The Minerals \& Metals Society.

[8] Lis, A.K., Garcia, G.I., DeArdo. A.J. 20-24 September 1992. "The Effect of Homogenization Treatment and Cooling Rate on the Transformation Characteristics of Alloy 718 " presented at the International Symposium on Superalloys. 